\title{
Using Business Entrepreneurship Practices to Engage Middle School Stu- dents in STEM Learning: Three Years' Perspective
}

\section{Dr. Jidong Huang, California State University, Fullerton}

Dr. Jidong Huang is a Professor of Electrical Engineering at California State University, Fullerton. His research had been supported by National Science Foundation (NSF), Federal Aviation Administration (FAA) and multiple private companies. Currently, his research interests are focused on innovative approches for STEM learning; robotics; the design of high-precision, integrated navigation system with high integrity; and their indoor/outdoor applications. He is a member of American Society of Engineering Education (ASEE), Institute of Navigation (ION), and a senior member of Institute of Electrical and Electronics Engineers (IEEE). 


\title{
Using Business Entrepreneurship Practices to Engage Middle School Students in STEM Learning: Three Years Perspective
}

\author{
Jidong Huang \\ Electrical Engineering Department \\ California State University, Fullerton \\ John Kuscera \\ Arroyo Research Services \\ John Jackson \\ Center for Entrepreneurship \\ California State University, Fullerton \\ Pradeep Nair \\ Computer Engineering Program \\ California State University, Fullerton \\ Amy Cox-Petersen \\ Elementary and Bilingual Education Department \\ California State University, Fullerton
}




\title{
Using Business Entrepreneurship Practices to Engage Middle School Students in STEM Learning: Three Years Perspective
}

\begin{abstract}
STEM-Inc is a 3-year NSF ITEST project designed as an after-school program targeting 7th and 8th grade students from traditionally underrepresented groups. This project created a simulated technology business 'incubator' in an afterschool program for middle school students at the Anaheim Union High School District in California. Its goal is to make middle school students and their parents aware of STEM career paths in addition to engage and attract the students to STEM fields and careers. To this end, the project focuses on getting the students involved in group activities to develop solutions for real-world problems that involve Engineering, Computer Science and Business concepts.

Toward this goal, business entrepreneurship practices, including the traditional new-venture creation approach and the emerging Lean startup approach, have been applied to stimulate and engage students in STEM learning. Both approaches offered students ways to look into the inherent value of STEM learning and provided them the opportunity to engage in business development activities such as idea generation, fast pitch, design thinking and business planning. In addition, lean start up approach provided students ways to interview potential customers and quickly make pivots in their plan for delivering a product or solution to potential customers fast and efficiently. According to data collected in the project, such entrepreneurship practices well enhanced the overall STEM learning experiences of students.

As a design and development project, research questions in STEM-Inc frame formative data collection and analysis to address aspects of the design that worked and others that require revision. Summative measures focus on student learning outcomes, as well as student attitudes toward science and engineering and self-efficacy.

This paper examines the overall STEM-Inc project design and outcomes, especially the year over year changes in project implementation based on both research needs and findings from prior year. Results from three years of project implementation showed positive indicators in both formative and summative data, which supported the use of business entrepreneurship practices for engaging middle school students, especially those from underrepresented groups, in STEM learning.
\end{abstract}

\section{Introduction}

STEM workers drive America's innovation and competitiveness by generating new ideas, companies and industries. The National Science Board (2010) cites longitudinal data showing that intellectually talented individuals who can be identified at an early age and then supported in their learning generate a disproportionate number of Fortune 500 patents, peer-reviewed STEM publications and other creative achievements, and comprise a disproportionate number of tenured 
academic faculty at top universities. Developing future stem innovators, the board declares, is nothing less than an economic imperative.

Unfortunately, as students go through school, their interest in STEM fields begins to wane, particularly by middle school. This attitudinal decline can begin at age 11 , but researchers have found differences between middle school students' attitude toward science generally and their attitude toward formal school science, which may stem from science that is not presented in a way that is culturally or developmentally interesting to students (Osborne et al., 2003).

To improve STEM interest, students must be 1) motivated to pursue STEM studies; 2) have time, resources and opportunities to learn and practice STEM skills; and 3) see the connections between STEM knowledge and the real world so they can envision careers for themselves (Thomasian, 2012). The President's Council of Advisors on Science and Technology (PCAST, 2010) recommends inspiring students to learn STEM subjects by creating opportunities for inspiration through individual and group experiences outside the classroom.

Companies in STEM industries also need employees with backgrounds in other disciplines, particularly business and entrepreneurship. Furthermore, entrepreneurship education can be a fundamental tool for helping low-income young people to see a bigger future for themselves (Network for Teaching Entrepreneurship (NFTE), 2013). Unfortunately, most youth have little or no knowledge of these fields. Fewer than half of US high school graduates take an economics course (Walstad, 2001), and while many educational programs have the goal of teaching engineering and computer science (Malyn-Smith \& Colón-Bacó, 2012), fewer teach the connection between STEM fields and business/ entrepreneurship, even though scientists and engineers operate in a global marketplace.

Consistent with the literature, STEM-Inc is an NSF ITEST afterschool program that engages $7^{\text {th }}$ and $8^{\text {th }}$ grade students, especially those from traditionally underrepresented groups, in engineering and computer science with real-world activities that relate to their own lives and inspire them with opportunities for STEM careers. A collaboration between California State University, Fullerton (CSUF) and Anaheim Union High School District (AUHSD), the STEMInc concept is to encourage students to think creatively and act as entrepreneurs in an informal, applied learning setting that emulates a technology business incubator (Huang et al., 2016; Huang et al., 2017).

STEM-Inc's goal is to make middle school students and their parents aware of STEM career paths in addition to engage and attract the students to STEM fields and careers. To this end, the project focuses on getting the students involved in group activities to develop solutions for realworld problems that involve Engineering, Computer Science and Business concepts.

Results from STEM-Inc on different aspects of the project based on individual year's implementation have been documented in several papers (Huang et al., 2016; Nair et al., 2016; Huang et al., 2017). This paper examines the overall STEM-Inc project design and outcomes, 
especially the year over year changes in project implementation based on both research needs and findings from prior year.

\section{Program Design}

Led by the college student mentors from CSUF in the field of engineering, computer science and business entrepreneurship and teachers from the four participating junior high schools, the STEM-Inc regular after-school program was offered in AUHSD, twice a week, two hours each time from early-October to early-May, for three academic years from 2014 to 2017.

On the engineering side, students went through a series of tutorials and trainings to develop skills and learn about engineering topics with experiences in the following.

- 3D modeling, design and printing: Students learned the fundamentals of 3D design using Sketchup software (http://www.sketchup.com); and worked on printing actual 3D objects, for example, keychain with names and STEM logos.

- Mobile App development: Students were taught on the use of web-based MIT App Inventor tool (http://appinventor.mit.edu); and were given the chance to test the examples and design their own mobile applications on Android-based tablets.

- Robotics: Students learned how to assemble the Arduino-based robotic car kit; and integrate electronics and sensors onto the robot to make it functioning different ways through C programming on Arduino.

- Robotic car racing: Students in groups were challenged to design a mobile app-controlled robotic car through Bluetooth communications for a racing contest at each school.

- Engineering games and activities: From time to time, students were introduced to engaging engineering activities, for example, air pressure powered paper rockets, marshmallow launchers, and spaghetti towers.

- Engineering design projects: As a cumulative experience, students worked in groups to identify and seek engineering-based solutions to real-world problems; and accordingly make prototype products to meet both engineering and business requirements.

On the entrepreneurship side, the goal is to help students identify the business value of the engineering product they conceive, design and implement through the engineering activities; and seek ways to promote the product through new venture creation. Toward this goal, business entrepreneurship practices, including the traditional new-venture creation approach and the emerging Lean startup approach, have been applied to stimulate and engage students in STEM learning with experiences in the following.

- Introduction to business, in which students became familiar with common terminology used in business and entrepreneurship. 
- Business planning: Students engaged in developing a small business plan for their engineering products with consideration of customers, market analysis, revenue streams, competitors, product differentiation and marketing.

- Team building: Students were grouped into teams of 4-6; and each individual student was assigned a dedicated role, such as $\mathrm{CEO}, \mathrm{CMO}, \mathrm{CFO}, \mathrm{COO}$ and engineer.

- Business interviews, for those students at Lean startup schools to interview potential customers on their project idea and design. In turn, they were asked to modify project design based on feedbacks received at the interviews.

- Effective communication: Students were engaged in activities such as Fast Pitch competitions to pitch their project design ideas to the rest of the class within 60 seconds or less. The rapid form of communication gave the students practice in explaining their ideas in a clear and effective manner.

- Design thinking: Students were introduced to Stanford's Design Thinking methodology. In this exercise, students learned about failing fast, fast prototyping and the importance of getting customer feedback.

These Entrepreneurship practices offered students ways to look into the inherent value of STEM learning and provided them the opportunity to develop critical career-readiness skills such as creativity, critical thinking, communication and collaboration (NEA, 2017).

In addition, compared to traditional new venture creation approach, the Lean start-up approach provided students ways to interview potential customers and quickly make pivots in their plan for delivering a product or solution to potential customers fast and efficiently (Ries, 2011). The premise of lean start-up is that business must form a hypothesis; then interact with potential customers before coming up with a solution. Based on those interviews, the company then creates specifications for a product that meets a confirmed need from potential customers and keeps returning to customers for feedback to refine it through a series of prototypes, starting with a "minimum viable prototype." Compared to traditional approach, lean start-up favors experimentation over elaborate planning, customer feedback over intuition and iterative design over traditional "big design up front" development (Blank, 2013).

\section{Student Demographics}

Student participants for the STEM-Inc project were recruited through multiple efforts (Huang, 2017). Recruiting flyers were created and distributed to the classes at the four participating schools via STEM-Inc teacher participants when the school year started. Additionally, a STEMInc open house and live engineering/computer science project demonstration with Q\&A session was held at each one of the four schools, mostly during the lunch hours in September for recruiting students. 
Through these efforts, a large number of applications were turned in; and were then screened by the STEM-Inc teachers and their school principals to ensure that underrepresented applicants were given higher priority. At each of the four school sites, about 30 to 40 students, resulting in a total of 120 to 160 students from $7^{\text {th }}$ and $8^{\text {th }}$ grade in AUHSD were recruited to participate in STEM-Inc program activities each year.

According to student demographics data (Appendix A), over the three years, STEM-Inc is increasingly recruiting students from historically underrepresented groups in STEM careers. Fifty-five percent (55\%) of STEM-Inc student participants identified themselves as African American or Latino in year 3, compared to $48 \%$ in year 2, and 30\% in year 1. Forty-five percent (45\%) also identified as female in year 3, compared to $49 \%$ in year 2, and 32\% in year 1 . Most of the STEM-Inc students had few or no experience in STEM and/or Business/Entrepreneurship prior to their participation in STEM-Inc. Across each of the three years, only about $20 \%$ of STEM-Inc students had experience in another after-school or summer STEM program. Percentage of students with prior experience in Business/Entrepreneurship is even lower, at 18\% in year $1,11 \%$ in year 2 and $10 \%$ in year 3.

The inclusion and high representation of underrepresented students in STEM-Inc provided an opportunity to develop intervention strategies not only fitting general student population but also working well for underrepresented groups. This is in line with the national effort for increasing the number of women, minorities, and underrepresented populations entering the STEM major/career pipeline due to the fact that America faces a demographic challenge with regards to its science and engineering workforce: minorities are seriously underrepresented in STEM, yet they are also the most rapidly growing segment of the population (NAS et al., 2011).

\section{Evaluation Method and Analysis}

The Arroyo Research Services (ARS) served as the external evaluator for STEM-Inc. In particular, ARS developed multiple instruments for evaluating: 1) the quality and fidelity of program development and implementation, and 2) the effectiveness of the program in terms of student outcomes.

The STEM-Inc evaluation instruments were built from psychometrically sound instruments and scales that include the Career Interest Questionnaire and Modified STEM Semantics Survey (Tyler-Wood et al., 2010), Entrepreneurial Self-Efficacy and Intention (Wilson et al., 2007), Student Attitudes toward STEM Survey (Mahoney, 2010); STEM Semantics Survey (TylerWood et al., 2010), Sources of Self-Efficacy Scale (Britner \& Pajares, 2006), and a 21st Century Skills Assessment/Rubric.

Specifically, the process evaluation was designed to measure both quality and intensity of STEM-Inc activities in order to monitor the short-term and formative results of activities and services, validate program components, and determine whether activities were of sufficient quality and intensity to influence intended outcomes. The process data were collected through 
project documents, attendance logs, a site visit with observations and interviews of an afterschool activity, and participant surveys. Post-, or end-of-program, surveys with students, mentors, teachers and parents also included formative items designed to inform next year's program development.

To assess program outcomes, ARS employed a number of measures (such as those for student interests and self-efficacy) and evaluation activities (such as those for student learning outcomes) across the four participating schools and between the two different interventions (a, traditional new venture creation approach; and b, Lean Startup approach), including survey data from students, college mentors, and teachers; as well as STEM-Inc advisory board members.

Furthermore, to assess the potential difference in project outcomes between the use of traditional new-venture creation approach and the emerging Lean startup approach for STEMInc entrepreneurship practices. The following were experimented at the four participating schools over the three years (table 1).

Table 1. Implementation Schedule of Entrepreneurship Practices, by school and year

\begin{tabular}{|c|c|c|c|c|}
\hline Ball JHS & Lexington JHS & Brookhurst JHS & South JHS \\
\hline $\begin{array}{c}\text { AY 2014 - 15 } \\
\text { (Year 1) }\end{array}$ & $\begin{array}{c}\text { Traditional } \\
\text { Venture Creation }\end{array}$ & $\begin{array}{c}\text { Traditional } \\
\text { Venture Creation }\end{array}$ & $\begin{array}{c}\text { Traditional } \\
\text { Venture Creation }\end{array}$ & $\begin{array}{c}\text { Traditional } \\
\text { Venture Creation }\end{array}$ \\
\hline $\begin{array}{c}\text { AY 2015 - 16 } \\
\text { (Year 2) }\end{array}$ & Lean Startup & Lean Startup & $\begin{array}{c}\text { Traditional } \\
\text { Venture Creation }\end{array}$ & $\begin{array}{c}\text { Traditional } \\
\text { Venture Creation }\end{array}$ \\
\hline $\begin{array}{c}\text { AY 2016 - 17 } \\
\text { (Year 3) }\end{array}$ & Lean Startup & Lean Startup & Lean Startup & Lean Startup \\
\hline
\end{tabular}

\section{Project Outcomes and Results}

As described above, data collection from STEM-Inc included mid-year formative surveys; afterschool site visits consisting of interviews and focus groups; fall (pre)/spring (post) surveys with participating students; and student learning outcome assessments consisting of engineering, computer science and business concepts measured by students' end of year self-assessment and rubric scores from advisory board members, mentors and teachers.

In this paper, the overall STEM-Inc project outcomes, especially the year over year changes are examined.

\section{Formative Results}

The first year (AY2014 - 15) for STEM-Inc had been focusing on developing, testing and implementing various project activities. Results from year 1 implementation of the project were previously documented in (Huang et al., 2016; Nair et al., 2016). Nevertheless, a focus group at the end of year 1 with college student mentors and STEM-Inc school teachers found that there were needs to document student progress in and satisfaction with the different program activities 
throughout the year for assessing the short-term project outcomes. Therefore, a mid-year student self-evaluation survey on STEM-Inc experiences was created and implemented in years 2 and 3. In addition, post-activity satisfaction survey was also implemented after various project activities (e.g. field trips, student competitions, and workshops).

According to these formative data, students had generally enjoyed the STEM-Inc afterschool program activities. For example, figure 1 shows the results from mid-year 2 evaluations. Over 80\% agreed or strongly agreed that they enjoyed working in groups, creating projects, learning about new technologies, and communicating with others. Over $70 \%$ agreed or strongly agreed that they were given time to research ways of solving problems, spent time testing ideas and/or plans, developed software or other products on a computer, and talked about STEM subjects to family and friends. Over 50\% agreed or strongly agreed that they enjoyed developing a business plan, spent enough time working on projects, and created documents on a computer.

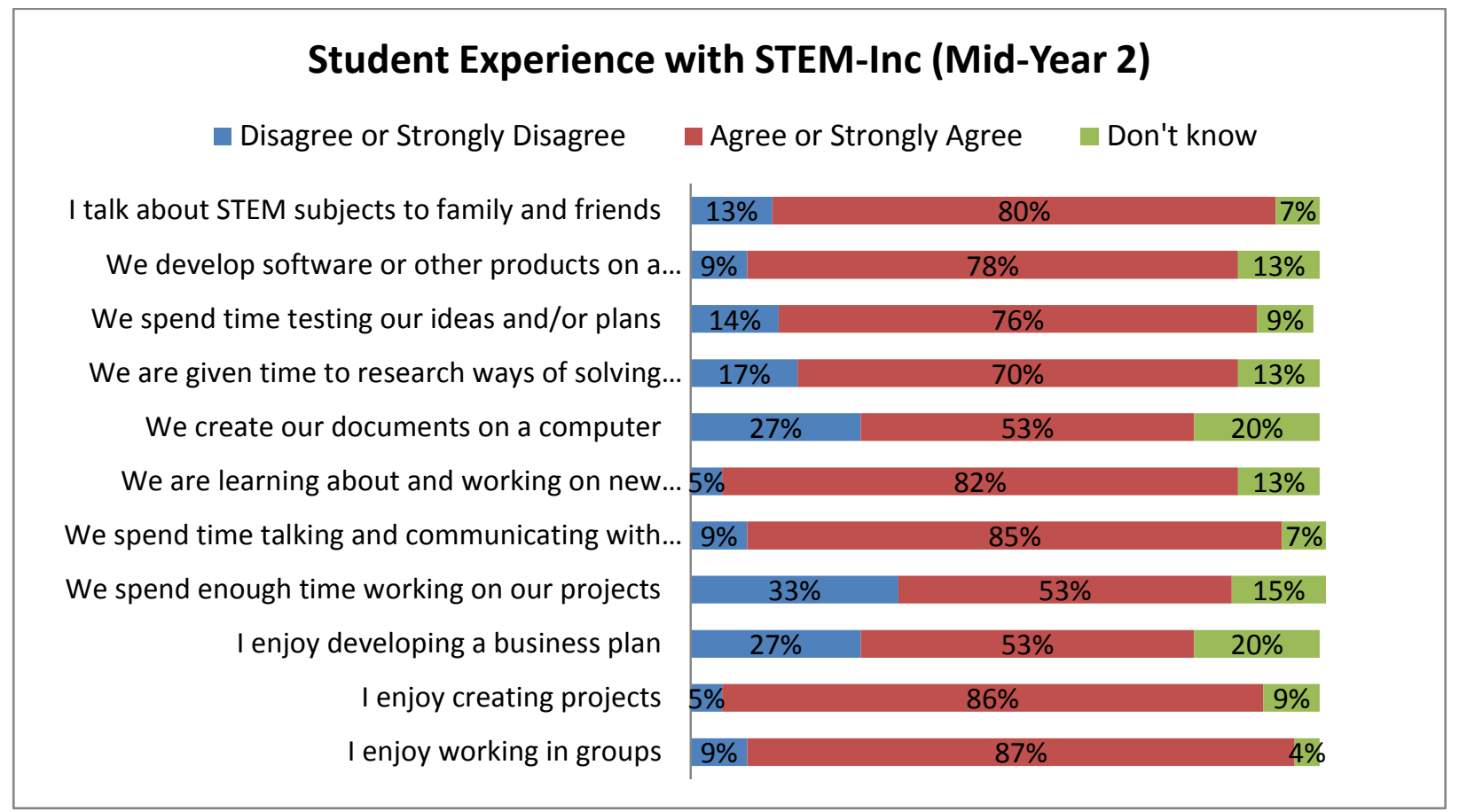

Figure 1. Student experience of STEM-Inc, mid-year 2

Similar results were obtained in year 3 from the mid-year survey (figure 2). For example, Over $90 \%$ agreed or strongly agreed that they were learning about new technologies; communicated with others; and enjoyed creating projects. Over $80 \%$ agreed or strongly agreed that they talked about STEM subjects to family and friends; were given time to research ways of solving problems, spent time testing ideas and/or plans, and enjoyed working in groups. 


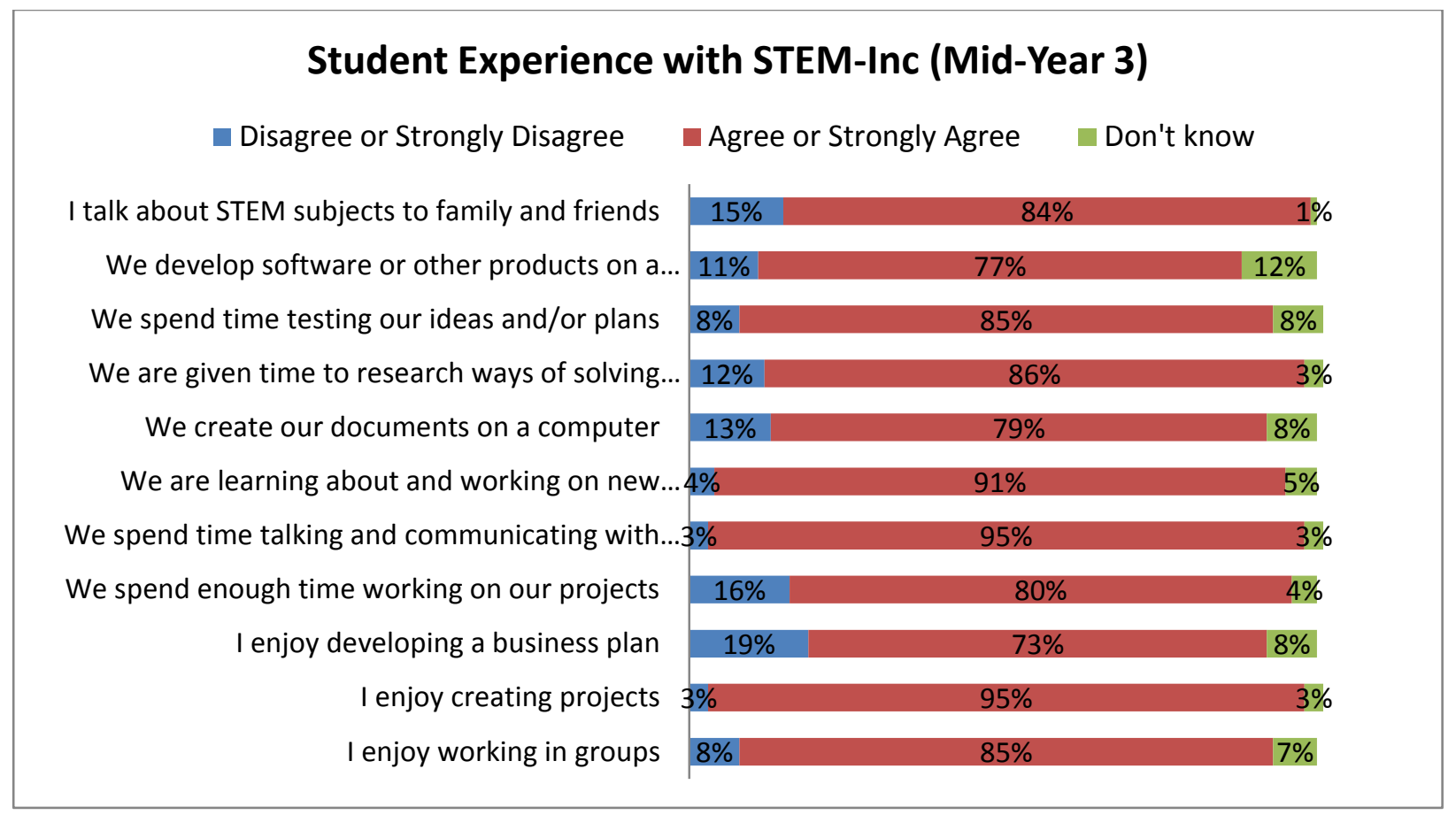

Figure 2. Student experience of STEM-Inc, mid-year 3

It's also worthwhile noting that based on results obtained from year 2, a number of improvements were made in year 3 to help enhance student learning experiences, for example improvements made for student peer leader training workshops; and professional development for college mentors and school teachers on project-based learning. In addition, all four schools used lean start-up approaches in year 3. As a result, almost all areas had seen improvements in year 3 with significant increases in the following: a) time to research ways of solving a problem (70\% to $86 \%)$; b) creating documents on computer (53\% to $79 \%)$; c) time to work on projects (53\% to $80 \%)$; and d) developing business plan (53\% to $73 \%)$.

When it comes to how STEM-Inc program activities helped students build up knowledge and interests in STEM and Entrepreneurship, the majority of STEM-Inc students reported either "satisfied" or "very satisfied". As an example, figure 3 demonstrates student's overall satisfaction level with STEM-Inc field trip to engineering facilities in Spring 2016 of year 2, in which $94 \%$ of the students believed that the activity was helpful or very helpful in acquiring knowledge of STEM content; $85 \%$ of the student believed that the activity was helpful or very helpful in developing interest in a STEM career. 


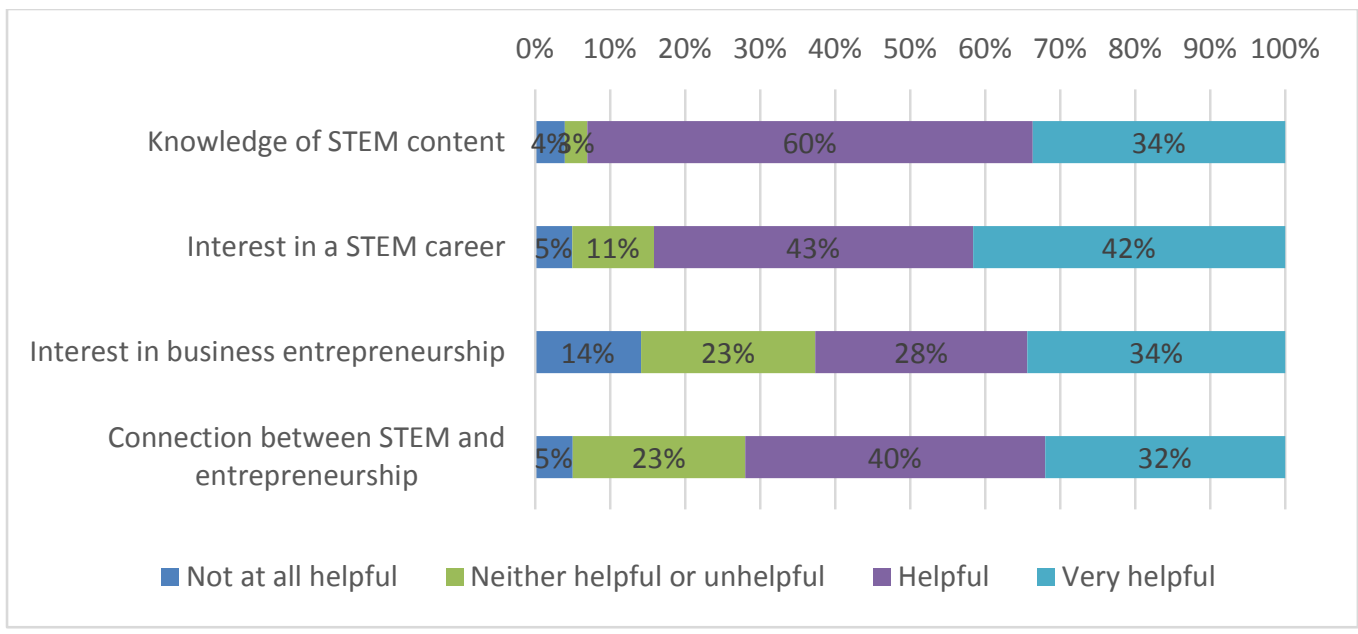

Figure 3. Student responses to "Please indicate the degree the event/activity helped you in the following:" for a field trip to engineering facilities in year 2

Similar results were obtained from the STEM-Inc field trip to a fast-pitch competition in year 3 (figure 4), in which $82 \%$ of the students believed that the activity was helpful or very helpful in acquiring knowledge of STEM content; $85 \%$ of the student believed that the activity was helpful or very helpful in developing interest in a STEM career. In addition, because this field trip is to participate in a fast-pitch competition where students from colleges and high schools present their business ideas within 60 seconds, it significantly helped developing student interest in business entrepreneurship ( $80 \%$ compared to $62 \%$ for the engineering field trip); and helped students understand the connection between STEM and entrepreneurship (79\% compared to $72 \%$ for the engineering field trip).

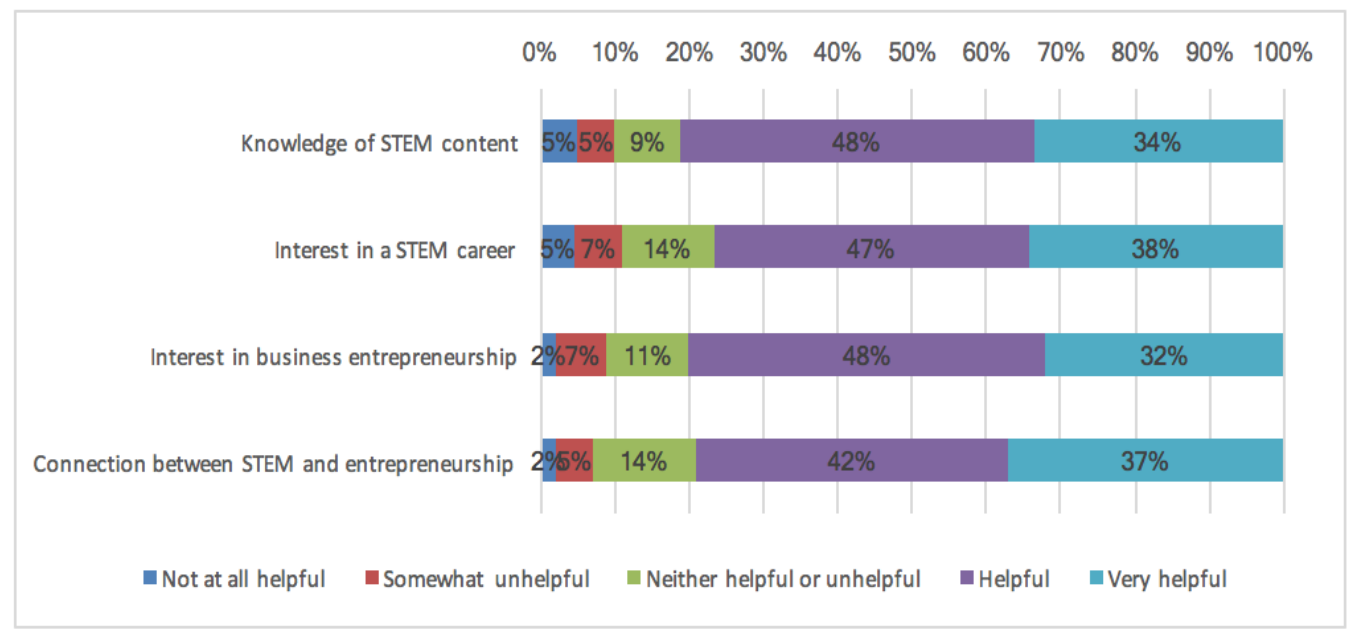

Figure 4. Student responses to "Please indicate the degree the event/activity helped you in the following:" for a field trip to a fast-pitch competition in year 3

\section{Summative Results}

Across the years, student interest towards subjects and fields in Engineering, Computer 
Science or Entrepreneurship was tracked by student self-surveys. Each field interest construct was measured using items on a 0 to 10 scale, with 10 reflecting the highest positive value ("Interesting," "Appealing,") and 0 indicating the closest negative value ("Boring", “Unappealing”).

As shown in table 2, students generally had the highest interest in engineering, followed by computer science and entrepreneurial. The interest in all three fields was consistent among years 1 and 2; but experienced a significant drop from year 2 to year 3. The exact reasons for this drop were unknown, but could be due to the adoption of lean start-up approaches at all schools when students were required to frequently revisit customer needs to refine their project design which might expose them to additional challenges in these subjects.

Table 2. Year-End Student Interest in Computer Science, Engineering \& Entrepreneurship, by year

\begin{tabular}{|c|c|c|c|c|}
\hline & Year 1 & Year 2 & Year 3 & Average \\
\hline Computer science field interest & 7.43 & 7.50 & 6.51 & 7.15 \\
\hline Engineering field interest & 7.81 & 7.88 & 7.51 & 7.73 \\
\hline Entrepreneurial field interest & 6.47 & 6.72 & 6.23 & 6.47 \\
\hline
\end{tabular}

In addition, student confidence $(1<2=$ low, $2<3=$ medium, $3<4=$ medium-high, $4<5$-high) towards engineering and entrepreneurship practices was assessed and documented in table 3 . Interestingly, a similar pattern as in table 2 was observed, in which student confidence in engineering and entrepreneurship practices improved from year 1 to year 2; but experienced a slight decline from year 2 to year 3. Again, the exact reasons for these changes were unknown, but could be the same ones as described above.

Table 3. Year-end Student Confidence in Engineering and Entrepreneurial Practices, by year

\begin{tabular}{|l|c|c|c|c|}
\hline \multicolumn{1}{|c|}{ Confidence in } & Year 1 & Year 2 & Year 3 & Average \\
\hline Engineering Practices & 3.88 & 4.51 & 4.25 & 4.21 \\
\hline Entrepreneurship Practices & 3.72 & 4.03 & 3.97 & 3.91 \\
\hline
\end{tabular}

Furthermore, to evaluate self-efficacy, students were asked to complete an 8-item selfassessment at the end of the program year regarding their degree of agreement to learning business/entrepreneurship skills from STEM-Inc activities. On a scale from 1="Strongly Disagree" to 5="Strongly Agree", students agreed to have learned most business/entrepreneurial skills (Means ranged from 3.7 to 4.2 in years 2 and 3; Figure 5). While self-efficacy in all areas were high, student believed that their strength areas were a) searching for new ideas; b) developing a business concept; c) developing a plan to build a prototype; and d) creating and achieving group goals; and their biggest weakness was in investigating feasibility of a new business concept. Again, a slight decline in all areas was observed from year 2 to year 3. 


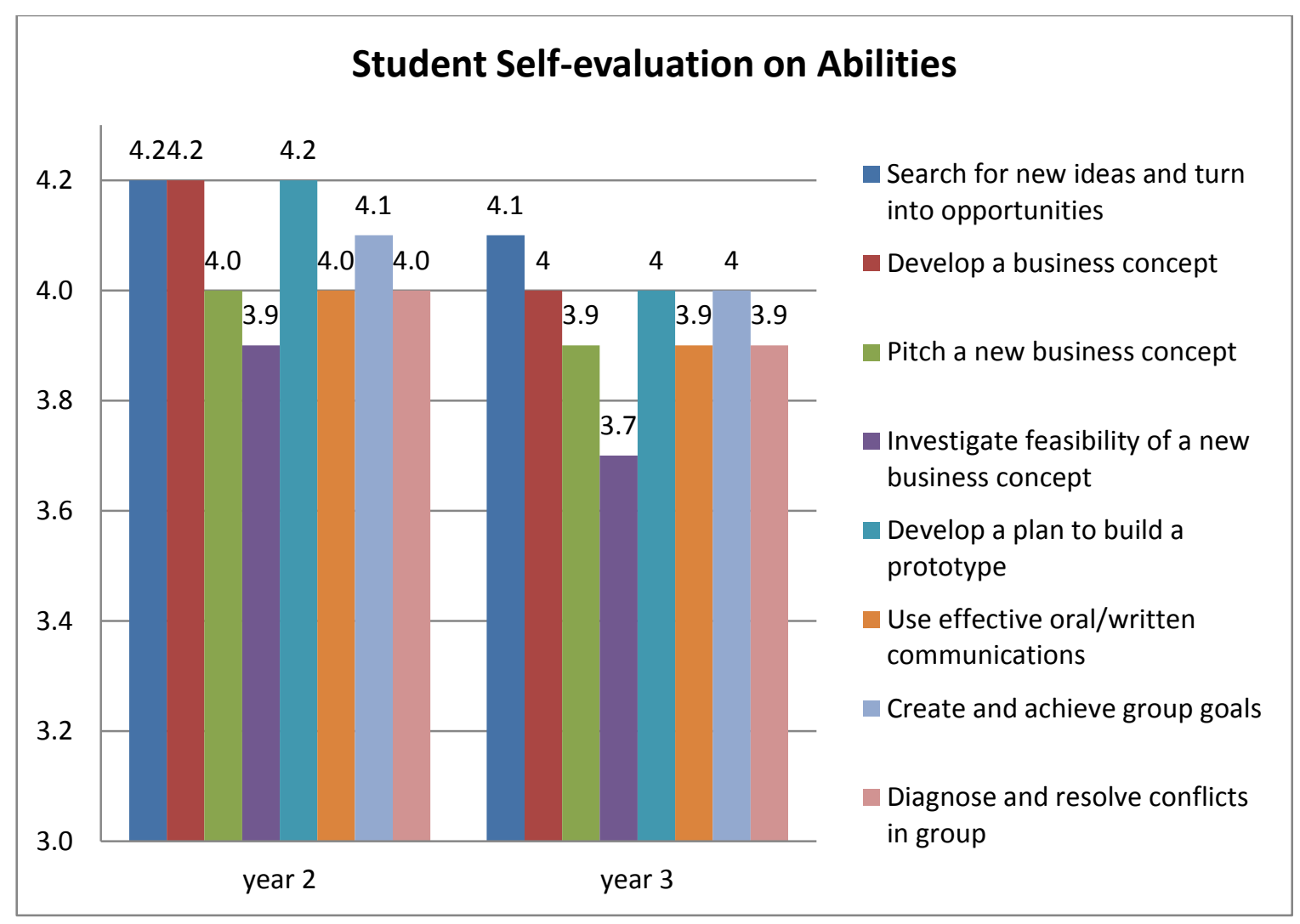

Figure 5. Student Self-evaluation on Business/Entrepreneurship Abilities

In addition, teachers were asked to complete the same 8-item assessment at the end of the program year regarding students' abilities in developing business/entrepreneurship skills from STEM-Inc activities on a scale from $1=$ "Strongly Disagree" to $5=$ "Strongly Agree." As shown in figure 6, teacher's evaluations on student abilities in almost all areas were medium to high (Means ranged from 3.2 to 4.1 in years 2 and 3), however significantly lower than student's selfevaluations. In teacher's opinion, students' strength areas were a) Pitching a new business concept; and b) developing a plan to build a prototype; and students' weakness areas were a) using effective oral/written communications; b) creating and achieving group goals; and c) diagnosing and resolving group conflicts. Again, a slight decline in almost all areas was observed from year 2 to year 3 . 


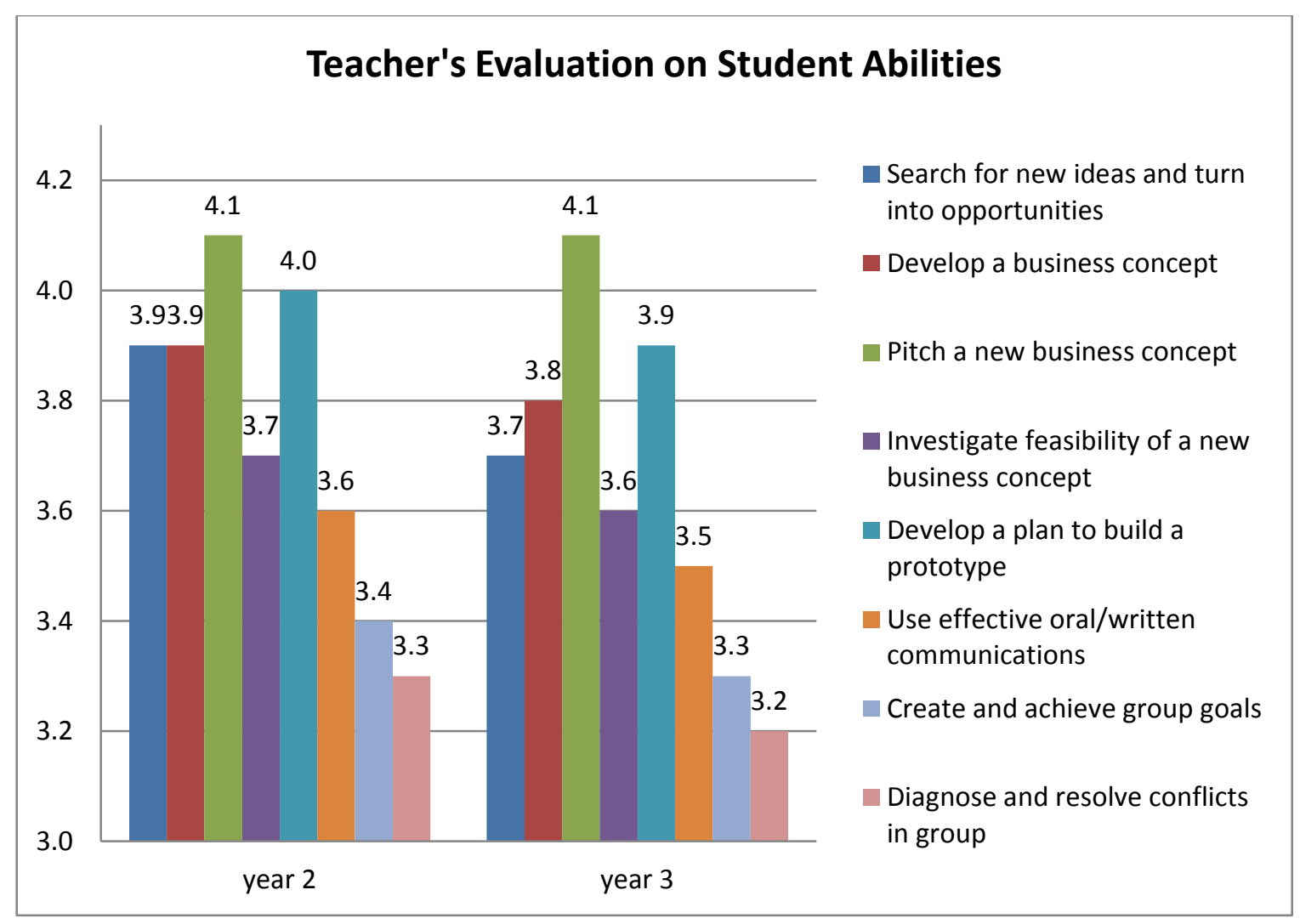

Figure 6. Teacher-evaluation on Student's Business/Entrepreneurship Abilities

Nevertheless, student interest towards careers in Engineering, Computer Science or Entrepreneurship had been consistently improved from year 1 to 3 as tracked by the end of year post-survey (Table 4). Each career interest construct in table 4 was measured using items on a 1 to 5 scale, with 5 reflecting the highest positive value ("Most Interested") and 1 indicating the closest negative value ("Least Interested"). Considering STEM-Inc project activities were almost identical over the three years, these consistent improvements from year 1 to 3 in all areas were most likely due to the continuous improvements made in project implementations, especially in those activities for career education, based on lessons learned from prior years.

Table 4. Year-End Student Career Interest, by year

\begin{tabular}{|c|c|c|c|c|}
\hline Career interest in & Year 1 & Year 2 & Year 3 & Average \\
\hline Business/management & 3.23 & 3.76 & 3.98 & 3.66 \\
\hline Starting own business & 3.60 & 3.93 & 4.13 & 3.89 \\
\hline Being a scientist/engineer & 3.90 & 4.26 & 4.43 & 4.20 \\
\hline Developing/maintaining computer software & 3.74 & 4.07 & 4.28 & 4.03 \\
\hline
\end{tabular}




\section{Discussions and Conclusions}

STEM-Inc is an NSF ITEST project that is designed to research the effectiveness of using business venture creation principles, including both the traditional new venture creation approach and the emerging lean start-up approach, to engage students in STEM learning and develop interests in STEM and related careers. It also helped developing abilities and career-readiness skills for students not only in STEM subjects but also in Entrepreneurship practices that are often needed in many STEM jobs. This applies to all students including those from traditionally underrepresented groups such as female and Latino.

STEM-Inc has attracted students with high interest and developed their confidence in STEM and entrepreneurship subject fields. Field interests were high at the end of each project year, with a three-year average of 7.15 in computer science, 7.73 in engineering, and 6.47 in entrepreneurship on a scale from 0 (least interested) to 10 (most interested). Similarly, student confidence with engineering and entrepreneurship practices was high, with a three-year average of 4.21 in engineering, and 3.91 in entrepreneurship on a scale from 1 (least confident) to 5 (most confident). In all areas, slight to medium increases were observed from year 1 to year 2 , while decreases were observed from year 2 to year 3 . The exact reasons for the drop were unknown, but could be due to the adoption of lean start-up approaches at all schools when students were required to frequently revisit customer needs to refine their project design which might expose them to additional challenges.

STEM-Inc has helped develop interests in engineering and entrepreneurship careers among participating students. Student interests towards careers in engineering, computer science and/or entrepreneurship had been consistently increased from year 1 to year 3 , with a three year average of 3.66 in business/management; 3.89 in owning a business; 4.20 in being a scientist/engineer; and 4.03 in developing computer software on a scale from 1 (least interested) to 5 (most interested). Again, STEM-Inc students had higher career interests towards engineering and computer science than entrepreneurship.

These results indicated that using entrepreneurship practices can be effective and has the potential to retain or improve student interests towards STEM at a formative age when career interests and motivation starts to develop.

STEM-Inc has helped students develop career-readiness skills and abilities in engineering and entrepreneurship among participating students, per self-report and teacher-evaluation. Participating students reported very high satisfaction with STEM-Inc activities including but not limited to working on new technologies; developing knowledge of STEM content; spending time testing ideas and plans; creating projects; communicating with others; and identifying connections between STEM and entrepreneurship as a result of STEM-Inc activities. Among various STEM-Inc activities, students had the highest satisfaction with the following: creating projects $(86 \%$ in year $2,95 \%$ in year 3$)$; working in groups $(87 \%$ in year $2,85 \%$ in year 3); communicating with others ( $85 \%$ in year $2,95 \%$ in year 3); and learning about and working on new technologies ( $82 \%$ in year $2,91 \%$ in year 3 ), indicating the need of 
addressing these elements for designing effective STEM-learning programs at Junior high level.

Interestingly, when it comes to the abilities developed in STEM-Inc, students identified areas of strength and weakness different from teachers; and the ratings from teachers were consistently lower than student self-evaluations. Student believed that their strength areas were a) searching for new ideas; b) developing a business concept; c) developing a plan to build a prototype; and d) creating and achieving group goals; and their biggest weakness was in investigating feasibility of a new business concept. In teacher's opinion, students' strength areas were a) Pitching a new business concept; and b) developing a plan to build a prototype; and their weakness areas were a) using effective oral/written communications; b) creating and achieving group goals; and c) diagnosing and resolving group conflicts. This clearly shows that students and teachers have different perceptions; such discrepancy shall be kept in mind when designing STEMlearning projects; and communication towards mutual understanding among students and teachers are often needed for ensuring effective teaching and learning.

In general, STEM-Inc students had higher interest and confidence towards engineering than entrepreneurship, which is understandable since STEM-Inc essentially is a project for STEM learning; and entrepreneurship has been used as a tool to engage students in STEM learning. However, it is worthwhile noting that activities incorporating both engineering and entrepreneurship (such as the field trip to a fast pitch competition where students present business ideas with engineering solutions) can better serve students than engineering only activities (such as a field trip for engineering lab tours), since the blend activity not only helps students develop STEM knowledge and career interest, but also helps students develop interest in entrepreneurship and understand the connection between STEM and entrepreneurship.

Although the exact reasons were unknown, year-over-year changes were observed in STEMInc project outcomes, including both positive and negative ones. These changes could result from either program activity changes (e.g. adoption of different entrepreneurship practices) or improvements made over the years (e.g. professional development for college mentors and teachers). Further research to identify and study factors contributing to these changes is worthwhile as it will help understand what results in the improvements and what has not. This also indicated that although summative evaluations are good for assessing overall project outcomes, periodic formative evaluations such as frequent pre- and post-tests are often needed for better understanding changes in student learning and interest, which will not only help identify the factors contributing to the changes but also can help ensure continuous improvements.

\section{Acknowledgements}

The research in this paper was supported by an ITEST (Innovative Technology Experience for Students and Teachers) grant from National Science Foundation with grant number DRL- 
1433851. In addition, the authors would like to thank all project staff including the AUHSD teachers \& administrators, CSUF college student mentors, and the project evaluator: Arroyo Research Services for their contributions to this research.

\section{References}

1. Blank, S. (2013). Why the lean start-up changes everything. Harvard Business Review, May 2013, 3-9.

2. Britner, S. L., \& Pajares, F. (2006). Sources of science self-efficacy beliefs of middle school students. Journal of Research in Science Teaching, 43(5), 485-499.

3. Huang, J., A. Bernal, J. Jackson, Y. Lu, \& A. Cox-Petersen (2016): Integrating STEM Education with Entrepreneurship Practices at Middle Schools: Feasibility Study and Preliminary Results, Proceedings of Hawaii University International Conference on STEAM \& Education, Honolulu, HI, June 2016.

4. Huang, J., J. Jackson, P. Nair, \& A. Cox-Petersen (2017): Using Lean Start-Up Approach to Integrate Engineering Education with Entrepreneurship Practices at Middle Schools, Proceedings of the 124 $14^{\text {th }}$ ASEE (American Society on Engineering Education) Annual Conference and Exposition, Columbus, $\mathrm{OH}$, June 2017.

5. Mahoney, M. P. (2010). Students' attitudes toward STEM: Development of an instrument for high school STEM-based programs. The Journal of Technology Studies, 36(1), 24-34.

6. Malyn-Smith, J., \& Colón-Bacó, E. (2012). ITEST engineering model: Building a better future for STEM learning. Report. iTEST Learning Resource Center.

7. Nair, P., Huang, J., J. Jackson, A. Cox-Petersen \& C. Elliott (2016): First-Year Engineering Experiences of the STEM-Inc Project, Proceedings of First Year Engineering Experience (FYEE) 2016 Conference, Columbus, OH, August 2016.

8. National Academy of Sciences (NAS), National Academy of Engineering (NAE), and Institute of Medicine. (2011). Expanding Underrepresented Minority Participation: America's Science and Technology Talent at the Crossroads. Washington, DC: The National Academies Press.

9. National Education Association (NEA), (2017). Preparing 21st Century Students for a Global Society: An Educator's Guide to the "Four Cs". Obtained from http://www.nea.org/assets/docs/A-Guide-to-Four-Cs.pdf

10. National Science Board (2010). Preparing the next generation of STEM innovators: Identifying and developing our nation's human capital. Arlington, Virginia: National Science Foundation, Information Dissemination Branch, p. 8.

11. Network for Teaching Entrepreneurship (2013). The NFTE difference: Youth entrepreneurship education works. Special report. New York: NFTE.

12. Osborne, J., Simon, S., \& Collins, S. (2003). Attitudes towards science: a review of the literature and its implication. International Journal of Science Education 25(9), 1049-79. 
13. President's Council of Advisors on Science and Technology (PCAST). (September 2010). Prepare and inspire: K-12 education in science, technology, engineering, and math (STEM) for America's future. Report to the President.

14. Ries, E. (2011). The Lean Startup: How Today's Entrepreneurs Use Continuous Innovation to Create Radically Successful Businesses. Crown Business.

15. Thomasian, J. (2012). The role of informal science in the state education agenda. Issue Brief. NGA Center for Best Practices.

16. Tyler-Wood, R. Knezek, G., \& Christensen, R. (2010). Instruments for assessing interest in STEM content and careers. Journal of Technology and Teacher Education 18 (2), 341363.

17. Walstad, W. B. (2001). Economics Education in U.S. High Schools. The Journal of Economic Perspectives 15 (3), 195-210.

18. Wilson, F., Kickul, J., \& Marlino, D. (2007). Gender, entrepreneurial self-efficacy, and entrepreneurial career intentions: Implications for entrepreneurship education.

Entrepreneurship Theory \& Practice, 31(3), 387-406.

\section{Appendix A: STEM-Inc Student Demographics}

Figure A.1 shows STEM-Inc student race information from year 1 to 3. Over the years, STEM-Inc has recruited a growing number of underrepresented minority students in engineering and computer science. As an example, the composition of Latino students in STEM-Inc has risen from $28 \%$ in year 1 , to $42 \%$ in year 2 and $53 \%$ in year 3.

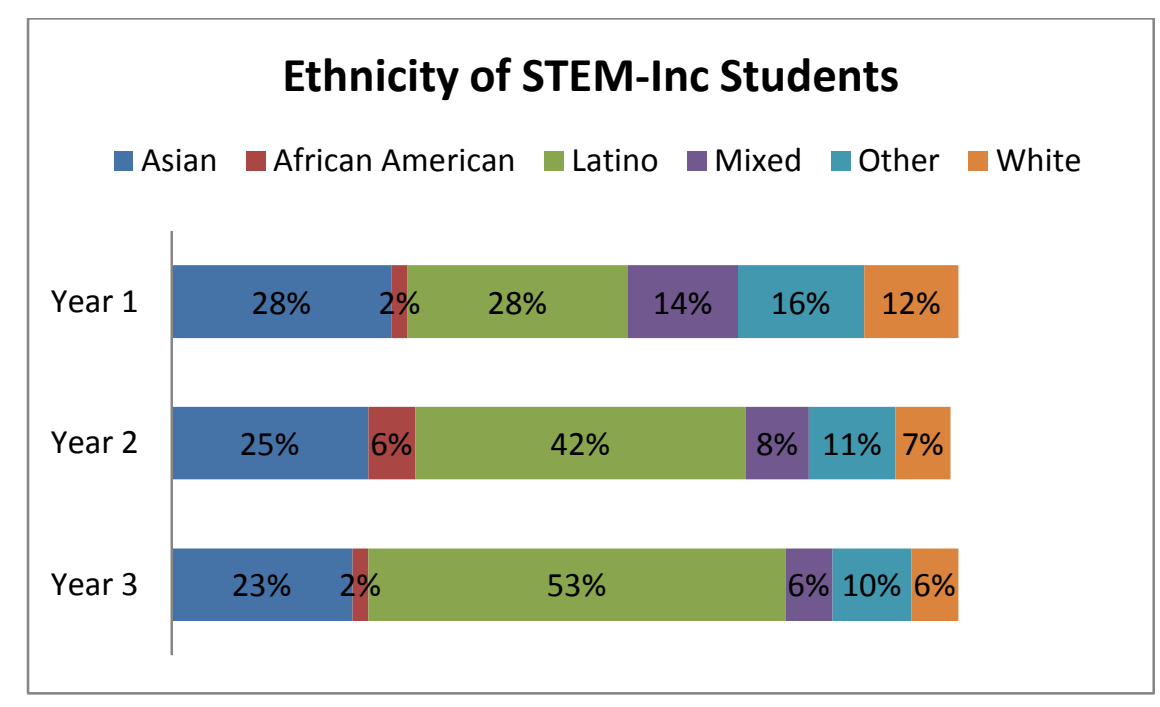

Figure A.1. Race of STEM-Inc student participants, by year

Figure A.2 shows STEM-Inc student gender information across the three years. Clearly, STEM-Inc had a higher proportion of female students in year $2(49 \%)$ and year $3(45 \%)$ compared to year $1(32 \%)$. 


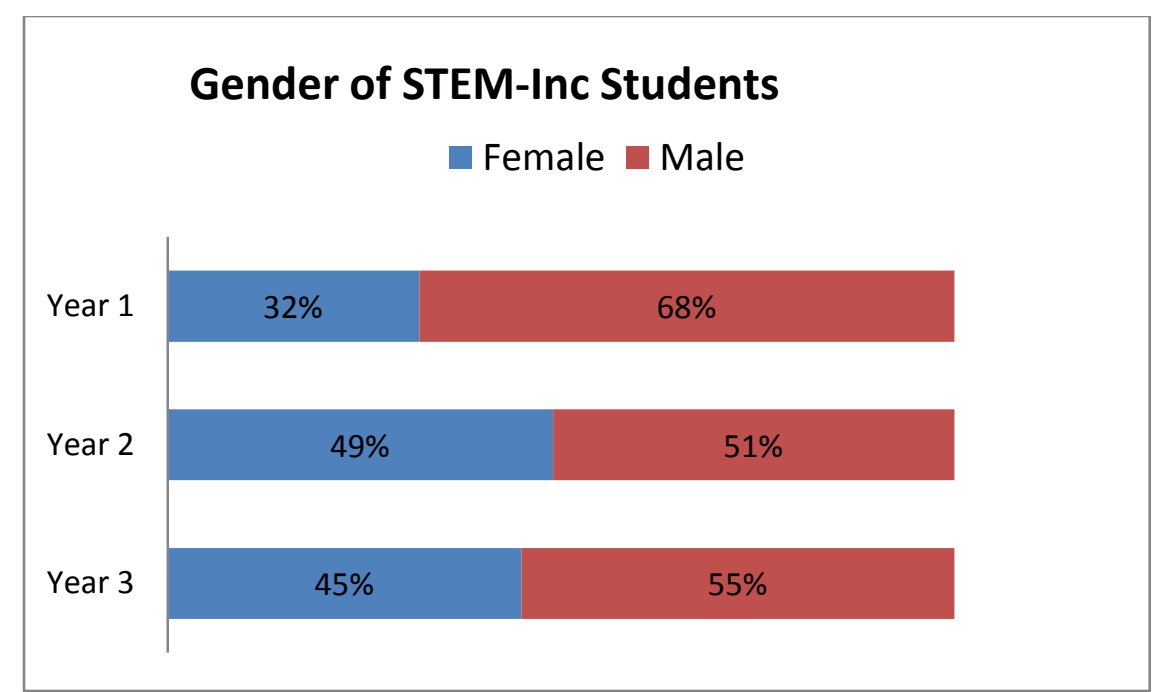

Figure A.2. Gender of STEM-Inc student participants, by year

In terms of student Grade distribution, year 3 participants were close to equally distributed between Grade 7 and Grade 8. In the year prior, most STEM-Inc. participants were from the seventh grade (Figure A.3).

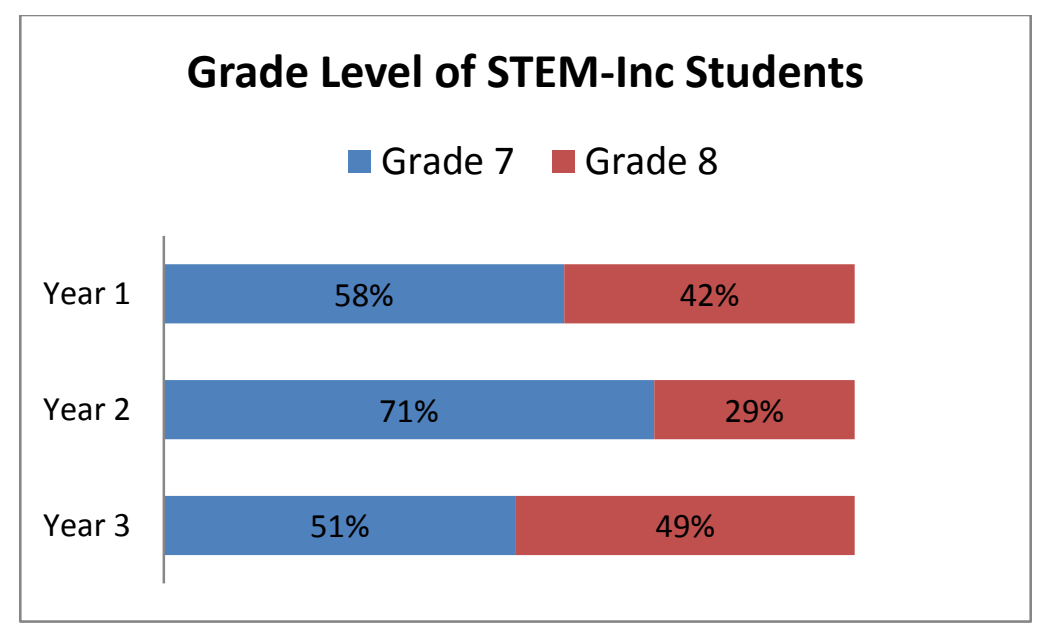

Figure A.3. Grade level of STEM-Inc student participants, by year

Furthermore, most of the STEM-Inc student participants had few or no experience in STEM and/or Business/Entrepreneurship prior to their participation in STEM-Inc (figure A.4). Across each of the three years, only about $20 \%$ of STEM-Inc students had experience in another afterschool or summer STEM program. Percentage of students with prior experience in Business/Entrepreneurship is even lower, at $18 \%$ in year 1, 11\% in year 2 and $10 \%$ in year 3 . 


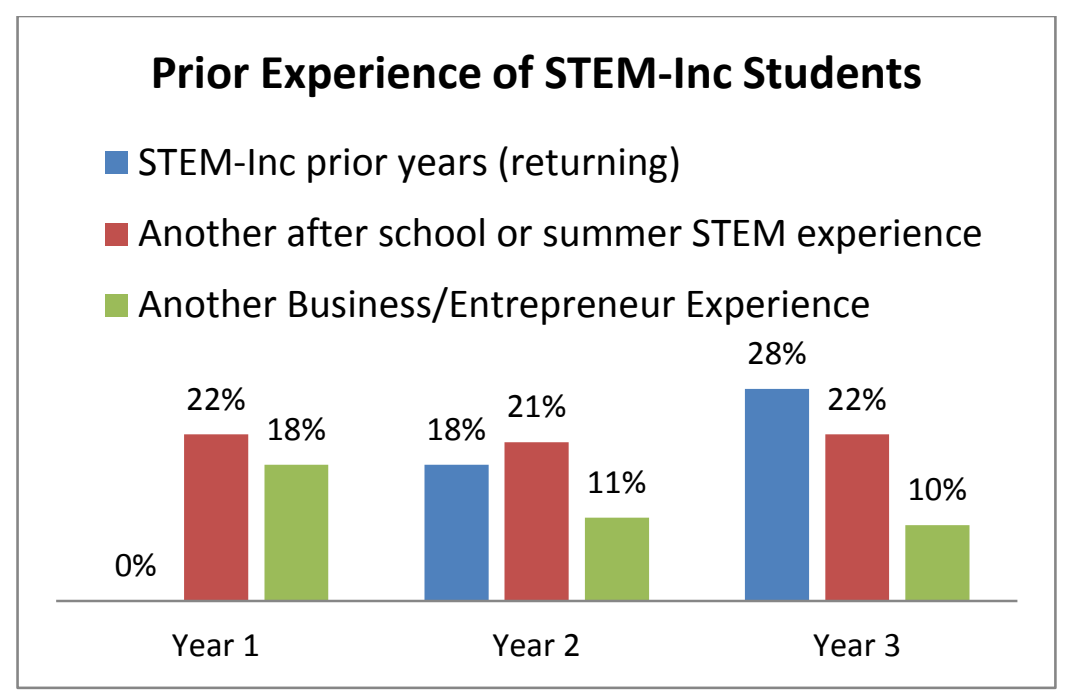

Figure A.4. Prior experience of STEM-Inc student participants, by year

From the above figure, it's also worthwhile noting that $18 \%$ of Year 2 students participated in the program in Year 1, where $28 \%$ of Year 3 students participated in the program in Year 2, clearly showing the capability of the program in retaining students. 